\title{
Turismo à luz do patrimônio cultural: uma abordagem sobre a identidade, memória e conservação dos Monólitos de Quixadá (CE)
}

\section{Tourism in the light of cultural heritage: an approach on the identity, memory and conservation of Monoliths Quixada (CE)} (Brazil)

\author{
Hermógenes Henrique Oliveira Nascimento
}

\section{RESUMO}

O presente trabalho tem o objetivo de analisar como a relação entre identidade, memória e conservação podem contribuir para 0 desenvolvimento do turismo utilizando elementos do patrimônio cultural do Monumento Natural Os Monólitos de Quixadá. Para isso, desenvolveram-se processos de investigação calcados principalmente em uma abordagem qualitativa com metodologia baseada na análise de conteúdo. Utilizou-se de pesquisas bibliográficas, em fontes documentais e empíricas. Essas consistiram em uma pesquisa de campo indagada a três grupos determinados pelo pesquisador que foram: da comunidade local inseridas na referida Unidade de Conservação (UC) (35 entrevistas), dos governos locais (5) e da iniciativa privada (10) envolvidos com o turismo e a cultura. E a partir dessa averiguação, identificaram-se aspectos da memória coletiva que contribuiu para conhecer a história local e determinando, dessa forma, quais os bens culturais na visão desses grupos que são representativos à cidade e que formam a identidade quixadaense constituindo no seu patrimônio. $O$ trabalho é estruturado em três capítulos: Turismo nas Unidades de Conservação e sua relação com a problemática de estudo; Apreciação do Legado Histórico e sua Importância para o Desenvolvimento Local: O caso de Quixadá/CE; A Herança dos Monólitos de Quixadá: Reflexões, Impactos e Transformação Turística. Em suma, diz-se que as discussões colocadas em tela são referentes a um contexto dialético e subversivo entre grupos sociais que refletem em uma transformação antagônica dos valores culturais existentes nessas áreas protegidas que são permeados pela memória e identidade da população ao longo do tempo acarretando no fator depreciativo da conservação do patrimônio local. Por fim, entende-se que para ocorrer o desenvolvimento sustentável do turismo com enfoque na cultura é imprescindível que a relação entre memória, identidade e conservação se concretize na sociedade local.

PALAVRAS-CHAVE: Turismo; Patrimônio Cultural; Memória Coletiva; Identidade; Unidades de Conservação. 


\section{ABSTRACT}

The aim of this work to examine how the relationship between identity, memory and conservation can contribute to the development of tourism using elements of the cultural heritage of Quixada. Therefore, procedures are developed for research based mainly to a qualitative approach with methodology proposed by Bardin. The bibliographic used searches on documentary sources and empirical. These consisted of a local search asked the three groups that were determined by the researcher: the local community (35 interviews), government (5) and private initiative (10) involved with tourism. And from that investigation identified aspects of the collective memory that contributed to know the local history and determining thus what the cultural vision in these groups that are representative to the city and to form the tourense identity is in it's heritage. The work is divided into three chapters: Tourism in Protected Areas and its relationship to the study of the problem; Findings of Historical Legacy and its Importance for Local Development: The case of Quixada/CE; The Heritage of monoliths Quixada: Reflections, Impacts and Tourism Transformation. In short, it says that the discussions are put on screen for a logical and subversive connection between social groups that reflected in a opposite transformation cultural values existing in the city that are conducted the memory and identity of the population over time causing the devalued factor the conservation of local heritage. Finally, it understood that to occur sustainable tourism development with a focus on culture is essential that the relationship between memory, identity and conservation firm in local society.

KEYWORDS: Tourism; Cultural Heritage; Collective Memory; Identity; Protects Areas.

\section{Contextualização inicial}

$\mathrm{Na}$ academia é destacado o caráter multidisciplinar da atividade turística, comprovando-se também na prática, pois ela é vista pela diversidade dos setores envolvidos, tanto da esfera governamental, quanto da privada. Talvez seja por isso que no âmbito dos conceitos e definições de turismo exista uma enorme complexidade, o que tem justificado a dificuldade de se ter um conceito que atenda aos seus diversos aspectos.

Para iniciar as discussões neste trabalho, cabe-se enunciar a concepção de turismo de Beni (2001), em que agrega a essa definição; as dimensões econômica, técnica e holística. Da mesma forma, no cotidiano, o turismo vem ocupando diversas categorias, seja de atividade econômica, social, cultural, meio de proteção e/ou degradação ambiental, dentre outras.

Para Beni (2001), turismo é um conjunto de equipamentos, bens e serviços de alojamento, de alimentação, de recreação e lazer, de caráter artístico, cultural, social ou de outros tipos, capaz de atrair e assentar numa determinada região, durante um período determinado, um público visitante. 
Ao longo do século $\mathrm{XX}$, com o aumento da prática do turismo pela sociedade e consequentemente o despertar para o estudo da atividade, surgiu-se várias outras definições para turismo inclusive com uma ampliação em sua complexidade, como se vê na definição proposta pelo antropólogo Jafar Jafari (apud BENI, 2001, p.36):

"é o estudo do homem longe de seu local de residência, da indústria que satisfaz suas necessidades, e dos impactos que ambos, ele e a indústria, geram sobre o ambiente físico, econômico e cultural da área receptora".

No curso do século $X X$, os entendimentos de cultura e história passaram por significativas modificações que repercutiram na compreensão dos bens considerados patrimônios.

Para compreender melhor essas mudanças Canclini (1994) conceitua que, o patrimônio inclui a herança cultural de cada povo, os bens culturais produzidos pelos segmentos sociais em cada tempo histórico e também os bens culturais visíveis e invisíveis, tais como idioma, conhecimento, documentação, artesanato, entre outros.

Desde o final dos anos de 1950, o turismo tem se tornado uma importante variável na economia mundial. Ao longo das três últimas décadas, o turismo tem sido reconhecido por vários países como uma valiosa estratégia de desenvolvimento socioeconômico. Neste cenário, o turismo tem despontado como um instrumento importante de dinamização do setor de serviços, uma vez que, segundo a Organização Mundial do Turismo (OMT), a atividade obtém receitas mundiais anuais de mais de US\$ 400 bilhões. A OMT prever que em 2020, o turismo mundial deverá alcançar receitas de aproximadamente dois trilhões de dólares.

Desse modo, pode-se dizer que o turismo constitui uma possibilidade concreta de minimização das disparidades regionais (CRUZ, 2000). Assim, a atividade turística constitui alternativa capaz de impulsionar o crescimento e o desenvolvimento regional.

No entanto, apesar de reconhecer que o turismo exerce grande importância sobre a cultura de determinado país ou de determinada região, funcionando como atividade articuladora da organização sociocultural, no caso brasileiro ainda não há estimativas específicas para tal segmento do turismo, isto é, no Brasil existem poucos estudos que quantificam, com maior rigor, os impactos desse segmento sobre a cultura.

No mundo, estima-se que $10 \%$ seja a cota mínima de proteção de recursos pelas várias nações, sejam estas unidades agrupadas como unidades de proteção integral, cujo objetivo básico é preservar a natureza, sejam unidades de uso sustentável, onde se procura compatibilizar a conservação da natureza com as necessidades socioambientais das populações envolvidas. O Estado do Ceará já alcança 6,5\%, porção considerável do espaço cearense protegido e que dará respostas futuras aos esforços gerados para garanti-los. 
Nesse pano de fundo, tem-se as Unidades de Conservação (UC) que são áreas naturais sob regime especial de administração, criadas legalmente pelo Poder Público, com localização e limites definidos. Em geral, possuem características ecológicas ou paisagísticas especialmente importantes, com elevada riqueza de espécies de flora e fauna, presença de espécies raras, endêmicas ou ameaçadas de extinção, amostras representativas de diferentes ecossistemas, significativa beleza cênica, ou recursos naturais indispensáveis para o bem-estar das comunidades humanas. Atualmente, no Estado do Ceará, temos 24 (vinte e quatro) Unidades de Conservação e um Corredor Ecológico que são administrados pela Secretaria do Meio Ambiente - SEMA.

Em função da fragilidade dos diversos sistemas ambientais do Estado e os atributos bióticos e abióticos, estéticos ou culturais especialmente importantes para a qualidade de vida e bem-estar das populações humanas, - Governo do Estado vem adotando medidas que têm por finalidade a proteção e preservação da biodiversidade, geodiversidade e 0 disciplinamento do processo de ocupação, visando assegurar a sustentabilidade do uso dos recursos naturais.

O Monumento Natural Os Monólitos de Quixadá é uma Unidade de Conservação de Proteção Integral, com uma beleza cênica de grande valor paisagístico, ecológico e turístico que encerram os campos de inselbergs existentes na região. Os inselbergs da região, popularmente conhecidos como Curral de Pedras, apresentam-se em forma de serrotes (monólitos), construindo uma paisagem formada por relevos residuais distribuídos sobre áreas pediplanadas.

Mediante a realidade exposta, referente ao objeto de estudo precisase compreender a potencialidade existente na referida UC no que tange 0 seu acervo patrimonial, onde guarda relíquias históricas e monumentos que remontam à época da colonização portuguesa, pois, assim, o turismo em áreas protegidas abre perspectivas para a valorização e revitalização do patrimônio, do revigoramento das tradições, da redescoberta de bens culturais materiais e imateriais, muitas vezes reprimidas pela concepção consumista moderna.

A delimitação desse estudo foi orientada a partir da percepção de que a preservação do patrimônio cultural se apresenta como essencial para a memória da UC, na medida em que possibilita o reencontro com as raízes das suas comunidades e a reafirmação das suas identidades, bem como, transformando-se em potencial atrativo cultural no planejamento turístico municipal.

Sob essa ótica, o presente trabalho visa reconstruir um cenário, onde a atividade turística passa necessariamente pela questão da cultura local do território da UC, reforçando a necessidade em compreender as suas memórias, investigar as peculiaridades de seu patrimônio e estimular a participação da comunidade no que diz respeito à conservação do seu legado histórico. E sob essa temática apresenta-se como problema de pesquisa: Como a relação entre identidade, memória e conservação pode 
contribuir para o desenvolvimento do turismo com enfoque no patrimônio cultural da UC estadual?

O objetivo geral do trabalho é analisar como a identidade, a memória e a conservação podem contribuir para o desenvolvimento do turismo, utilizando elementos do patrimônio cultural do Monumento Natural Os Monólitos de Quixadá. Para o alcance desse objetivo, delinearam os seguintes objetivos específicos: averiguar se há identidade cultural da população com a sua cidade; compreender a importância histórica do patrimônio cultural da UC para o desenvolvimento local; avaliar a participação dos atores relacionados com o turismo na elaboração de políticas/ações para o turismo em UC; apontar os impactos positivos e negativos já existentes e potenciais em decorrência da atividade turística na UC.

Para Bomfim (2006), muitos autores têm percebido que a história humana acaba por predominar sobre os fatores naturais na configuração de regiões. Outros acrescentam, ainda, o sentimento de pertença com a consciência da tradição e de ideais comuns, considerando ainda que o binômio homem-meio ainda não foi incorporado como uma das grandes dimensões da identidade.

Logo, a identidade de um povo é primordial para a reversão da tendência em curso e seu fortalecimento serve como base para a valorização do lugar.

\section{A colcha de retalhos}

\section{Apreciação do legado histórico e sua importância para o desenvolvi- mento local: o caso de Quixadá (CE)}

A identidade cultural e a memória coletiva, bem como suas diferentes expressões na preservação do patrimônio intangível, são extremamente importantes para a compreensão do vínculo entre o patrimônio cultural e os direitos da coletividade.

Nesse contexto, os bens patrimoniais servem de apoio à memória, uma vez que o passado só existe porque se apoia nos objetos que lhe estão ligados. A materialidade do patrimônio cultural está intimamente relacionada a fatores imateriais que o exercício da memória coletiva pretende associar à formação identitária de um povo.

Pode parecer equivocado dizer que todos os bens integrantes do patrimônio cultural carregam um vínculo com a identidade e a memória das comunidades em que estão inseridos. Entretanto, não é difícil aceitar essa conclusão quando se verifica que a destruição de um bem cultural promove a passagem do material para o imaterial: é um ato de destruição do passado e daquilo que a construção coletiva da memória quer representar.

O homem, nas suas relações sociais, forma a teia de interações, trocas e harmonia com a terra em que vive, e constrói sua cultura em conjunto com paisagens, completando-as com a beleza e a grandeza das suas criações, destacando-se a inventividade do povo cearense, que respeita o ambiente e que convive diariamente neste recorte do Nordeste. 
A criação do município de Quixadá data do século XVIII, quando os índios Kanindés e Jenipapos, pertencentes ao grupo dos Tapuias, teve vencida a sua resistência, no momento em que Manuel Gomes de Oliveira e André Moreira Barros ocuparam as terras por eles habitadas. Em 1728, essas terras foram adquiridas, por compra, por Manoel da Silva Lima, conforme escritura de 18 de dezembro do ano citado. Em 1747, as terras foram vendidas a José de Barros Ferreira, que construiu casas de morada, capela e curral, bases da atual cidade de Quixadá, sendo considerado, o legítimo fundador da cidade. A fazenda prosperou e transformou-se em distrito do município de Quixeramobim, "podendo-se dizer que Quixadá teve seu início de história datado de 1747” (COSTA, 2002, p.12).

Quixadá, de 1870 até hoje, teve cinquenta e três governos municipais. O primeiro prefeito foi o fazendeiro Laurentino Belmonte de Queiroz, com mandato exercido de 1871 a 1873. Desde então, Quixadá passou por grande processo de crescimento econômico, adquiriu identidade própria e tornou-se polo de irradiação comercial, cultural e educacional.

De tal modo, há bens que não pertencem apenas a um indivíduo ou a um grupo. Eles são tão importantes que têm valor para a comunidade, para uma cidade, para um país. São produtos da cultura de um povo, de toda ação inteligente do homem, na tentativa de conhecer e de se adaptar ao meio ambiente. Foram criados, recriados, aprimorados e estabelecidos ao longo do tempo e da história. Os bens culturais são os elementos que diferenciam grupos e sociedades e ajudam um povo a compreender suas características e construir sua identidade. Para que se possa compreender a forma de vida de pessoas de uma comunidade faz-se necessária a análise do contexto cultural no qual ela foi gerada, e a sua subjetividade porque, segundo Motta (2006, p.27),

[...] cultura é linguagem, é código. Ela fornece um referencial que permite aos homens dar um sentido ao mundo em que vivem e as suas próprias ações. Ela designa, classifica, corrige, liga e coloca em ordem. Define os princípios de classificação que permitem ordenar a sociedade em grupos distintos, desde os grupos totêmicos até as categorias profissionais [...]

Considerar o espaço e o modo de interação entre as pessoas e os grupos, no seio da sociedade na qual eles se constroem e funcionam, é pressupor a existência de um laço social, de um sentimento de pertença. É necessário, porém, apreender-se como sujeito; reconhecer-se como ser que pensa, age, e é possuidor de vida. Esse sujeito, no entanto, é parte de uma coletividade sem a qual esse reconhecimento não ocorrerá. É na interação com o outro que ele toma consciência de sua existência no mundo, do seu fazer, das formas de agir e reagir sobre os impulsos naturais e a conquista de seu próprio destino histórico, do seu espaço geográfico. 
O homem como sujeito ativo, pertencente a uma sociedade, a uma comunidade, é pela práxis que se desenvolve. Pela cultura, ele se transforma e modifica a si mesmo e a natureza. Pela educação, ele aprimora seu trabalho, humaniza-se, socializa-se, constrói sua identidade.

Baseado nesses fundamentos e nas respostas colhidas por meio do questionário pode-se dizer que a identidade cultural do povo quixadaense é muito forte, genuinamente nordestina, representada pelos profetas da chuva ${ }^{1}$ pelos repentistas, pelo bumba-meu-boi, pelas festas populares, pelo artesanato, pelas crenças e crendices, o que proporciona o conhecimento dos hábitos culturais e a forma como o sertanejo se relaciona com os recursos naturais da Caatinga.

Mesmo se tendo ciência de que o sentimento cultural do povo quixadaense é forte, $64,44 \%$ de seus protagonistas, representados pelos participantes dessa pesquisa, afirmam que a cultura está sendo esquecida. As causas são as mais diversas, dentre as quais destacam-se a inexistência de políticas públicas, a falta de interesse político e da própria comunidade; a globalização de hábitos, atitudes e valores introjetados pelos jovens. Fazem coro a essa afirmação, os entrevistados comerciantes e comerciários, ao colocarem que o fator principal da não preservação da cultura são a falta de investimentos e de políticas públicas.

Os entrevistados da iniciativa privada, embora acreditem que há preservação da cultura, ressaltam a dificuldade nesse sentido por falta de incentivo do governo municipal. Entretanto, outra parte deste segmento tem opinião divergente. As pessoas afirmam que a cultura em Quixadá é preservada porque o povo vive cultivando sua cultura e sua gente; porque a população tanto preserva os costumes como as crenças, a fé e se orgulha da beleza que são os seus monólitos.

Há, também, entre secretários e comerciários, os que consideram que as pessoas têm em si espírito tradicional, por isso preservam bem os costumes, hábitos e crenças, e que esse trabalho conta com o apoio da população e das leis de preservação. Ainda com respeito a esse aspecto, argumenta-se que a preservação cultural se dá também por conta de instituições ali instaladas como as faculdades e o IFCE que procuram incentivar os movimentos culturais. As entrevistas consideraram a atuação efetiva da Fundação Cultural por meio dos eventos por ela realizados.

Em Quixadá, a cultura manifesta-se por meio das festas populares e religiosas, do artesanato e dos esportes, que na cidade são chamarizes para a visitação turística. Pela amostra da pesquisa, as festas tradicionais de maior visibilidade são: a quadrilha junina $(21,48 \%)$; o forró $(19,62 \%)$, o carnaval $(18,62 \%)$ e a vaquejada $(18,19 \%)$ da amostra pesquisada. Diante das respostas, as festas preferidas da população local e regional são a quadrilha e o forró, o que não poderia ser diferente, visto que, excetuando-se o carnaval que tem amplitude nacional, as demais fazem parte do folclore nordestino, pertencem à cultura regional e refletem as raízes de seu povo.

O artesanato aparece como um dos fatores de renda para a população. São confeccionados objetos com palha de carnaúba, madeira, couro, pedra sabão, cera, tintas, juta, arranjos de flores artificiais e 
reciclagem de jornais e papelão. Também incluem bordado, crochê, trabalhos em tecido, confecção de bonecas de pano, redes de pesca, bijuterias, pintura em tela e em tecido e redes de dormir.

Das pessoas da comunidade consultadas, $21,85 \%$, afirmam que 0 crochê é o artesanato mais comum em Quixadá, seguido do bordado, escolhido por $20,18 \%$ da amostra pesquisada. A pintura, em tela e em pano, também é reconhecida por, respectivamente, $17,61 \%$ e $13,49 \%$ da população que respondeu ao questionário. Outros tipos de artesanato fazem parte da cultura de Quixadá, porém sem muita expressão, como objetos em palha, madeira, couro e escultura em pedra.

Há ainda em Quixadá uma representação social singular. Várias são as manifestações culturais, algumas delas derivadas do imaginário popular. As pessoas acreditam em Objetos Voadores Não Identificados (OVNI) e, por isso, na região, a ufologia é assunto corriqueiro.

A paisagem natural de Quixadá, dotada especialmente de originais monólitos, configura-se como de uma beleza ímpar, inclusive, tem servido de cenário para diversas produções cinematográficas. Alguns filmes ${ }^{2}$ foram ali rodados, tais como: "O Cangaceiro Trapalhão", "O Quinze", "O Auto da Camisinha", o "Área Q", ora em exibição nos cinemas e "Gato Preto", ainda não estreado. A cidade possui poucos equipamentos culturais: o Museu Histórico Jacinto de Sousa, o Centro Cultural Rachel de Queiroz, com dois pavimentos, um teatro e um anfiteatro, que oferecem oficinas de audiovisual, música, teatro e artes plásticas. Entretanto, a população sente falta de incentivo por parte de órgãos do governo, em todas as esferas administrativas, e de parte da população.

A partir desse cenário, pode-se inferir que:

Transformando os recursos da região em arte, extraindo do solo, dos monumentos naturais, da fauna e da flora o seu sustento e, a partir desse manejo, mantendo a subsistência da comunidade, o nativo região de Quixadá torna possível uma exploração consciente e racional dos bens. E, no equilíbrio entre trabalho e meio ambiente, oferece 0 resultado de uma cultura profundamente enraizada, com produtos que revelam a criatividade e a versatilidade de artesãos populares, intimamente sintonizados com suas mais caras tradições (VON BEHR, 2007, p. 34).

Em Quixadá, como em outras cidades do interior, a cultura sobrevive no imaginário popular e é preservada, em parte, devido a transmissão oral de geração a geração, muito mais do que por iniciativas ou ações derivadas de políticas públicas, como se pode constatar nesta pesquisa. Há certo desinteresse pelas "coisas da terra" por parte das pessoas mais jovens que procuram outras formas de expressão cultural, copiando modas, modismos, atitudes, hábitos e comportamentos de outras regiões, tangidos pela força da mídia. As poucas atividades culturais resumem-se às festas populares como 
São João, festa da padroeira, encontro dos profetas das chuvas, carnaval e vaquejadas, as quais, de alguma forma, contribuem para o incremento do turismo na região.

Nas últimas décadas, a atividade turística tem se configurado como uma importante atividade econômica em todo o mundo, com implicações diretas na vida social e cultural de cidades e pessoas, gerando empregos, divisas e proporcionando contatos culturais e representações de diversas localidades.

Dessa forma, é importante se discutir acerca do turismo como prática social vivida por pessoas que buscam atendimento às suas necessidades mais diversas. É nesse aspecto que o turismo se sustenta e se desenvolve.

A criação ou escolha de espaços turísticos se funda na ótica do diferente, do belo, do exótico, do rústico, do histórico, do cultural, da religiosidade, aspectos que devem se contrapor à rotina do turista. Para atender a essa exigência, o turismo produz novas configurações geográficas, pelas relações produtivas do espaço, pela acumulação de bens e renda.

No cenário mundial, a atividade turística tem se transformado em meio de expansão do capital, consolidando-se através do consumo, da produção e reprodução do espaço social em um grande produtor e gerador de riquezas, o que contribui para a produção de espaços novos, independentemente de sua localização geográfica.

As atividades turísticas apresentam dois lados divergentes: da mesma forma que pode promover o crescimento local e regional, o turismo, ao se instalar nos espaços, transforma-os em lugares evidenciados como "da moda" e todo o patrimônio cultural, histórico e natural é vendido como objeto de prazer, de ócio, de cultura, de religiosidade. Nesse contexto são produzidas várias formas estruturais de paisagens e de negócios, provocando, muitas vezes, na população local um sentimento de nãopertencimento com consequente perda de sua identidade.

A indústria do turismo, nesse processo de criação, recriação e transformação do território para seu uso e exploração, entra em conflito com os habitantes locais. Mas, nem sempre essa indústria tem a força necessária para alijar do território ocupado a sociedade ou grupo social que o produziu. Isso se deve à existência de sentimentos contraditórios e, ao mesmo tempo, articulados entre o lugar e a cultura, entre o lugar e seus habitantes, os quais se expressam mediante diversas formas de resistência à quebra de suas tradições. Essa disputa faz com que o território construído para o turismo não seja exclusivo dele, mas também dos que nele vivem com suas diferentes formas de vida e de relações socioespaciais.

Com o turismo, as pequenas (e grandes) cidades se modificam e novas relações socioespaciais são estabelecidas entre os que lá vivem e os que ali chegam. Um novo espaço é (re)criado. Os lugares, com seus contrastes culturais e diferenciação geográfica, são as bases da exploração pelos agentes hegemônicos.

Faz-se necessário o estabelecimento de políticas públicas claras e objetivas, porque a atividade turística consegue estabelecer uma relação 
fragmentada e, ao mesmo tempo, articulada entre o lugar e o mundo. É nesse modelo paradoxal de relação que o turismo se materializa, pois usa dos recursos locais, da reestruturação dos espaços, das pessoas para produzir paisagens diversas e vendê-las, obtendo e acumulando capital. Portanto, a política para a expansão do turismo em qualquer espaço, seja nas pequenas, médias e grandes cidades, deve levar em conta os anseios da população ali residente, a preservação do meio ambiente e do patrimônio arquitetônico e cultural, além do desenvolvimento socioeconômico local e regional.

Constata-se que, o turismo no Nordeste cresce em ritmo acelerado e em todos os sentidos: na quantidade de turistas que visita a região e, consequentemente, no volume de capital gerado pela atividade. $O$ espaço turístico é, sobretudo, um espaço geográfico e constitui, portanto, "uma realidade objetiva, um produto social em permanente processo de transformação" (SANTOS, 1985, p.49).

Algumas cidades, por sua localização e situação geográfica, são propícias aos investimentos do capital, na forma de oferta de bens e serviços - a indústria do turismo e Quixadá é uma delas. Devido à beleza de suas paisagens, o município apresenta grande potencial para se desenvolver como polo turístico no Sertão Central, especialmente no que se refere ao ecoturismo e turismo cultural. As atividades turísticas ali desenvolvidas, ainda são tímidas, talvez pela falta de incentivo estatal ou de visão empresarial, fazendo com que se percam oportunidades de desenvolvimento, por meio da exploração dos recursos naturais. Não existem políticas públicas locais para implementá-las, sendo que os poucos empreendimentos ali instalados vêm de fora e são organizados por empresas que utilizam o espaço geográfico, seu relevo e paisagem para tal fim.

A natureza propiciou uma paisagem belíssima à região de Quixadá: seus monólitos, alguns em pleno centro da cidade ganham, na percepção dos indivíduos pesquisados, formas diversas e são usados para a prática de esportes radicais; uma vegetação de caatinga, que mesmo com um clima quente e seco, no inverno, enche os olhos com seu verdor e, no período de estiagem, mostra toda a beleza de uma natureza que espera renascer à primeira gota d'água caída do céu; um povo hospitaleiro e simples; um comércio pujante e em crescimento.

Porém, como frisado pelos pesquisados, faltam políticas públicas para o incremento de atividades turísticas mais sistemáticas e contínuas; faltam empreendedores e formação profissional mais focada nesse sentido; falta vontade política e investimentos para alavancar uma atividade que, se bem conduzida, pode oportunizar emprego e renda para a população local e regional. 


\section{Considerações finais}

\section{A herança dos Monólitos de Quixadá: reflexões, impactos e transformação turística}

Diante dos grandes desafios que acometem a civilização neste princípio de terceiro milênio, a discussão em torno dos rumos a serem tomados no trato das questões ambientais assume posição de destaque. Nunca esteve tão em pauta a preocupação com a preservação da vida no planeta, em suas mais variadas formas, e com o aprimoramento dos meios necessários à manutenção do patrimônio natural, dando margem a um maior envolvimento da sociedade na definição dos princípios que devem reger o seu relacionamento com o meio que a cerca.

Neste contexto, às Unidades de Conservação cabem papéis significativos quando buscam proteger espaços territoriais criados pelo poder público, delimitados com o objetivo de assegurar a conservação de seus recursos ambientais, possuindo características naturais relevantes, sendo submetidos a um regime especial de administração e adequada proteção.

Assim, tais espaços ambientais são porções delimitadas do território cearense, especialmente protegidas para garantir a preservação do meio ambiente e defender a biodiversidade.

Espera-se que as Unidades de Conservação sejam ampliadas, diversificadas e interconectadas, aliadas ao respeito cultural e saber especializado das comunidades tradicionais, e à promoção da qualidade ambiental e de vida para uma sociedade rumo à sustentabilidade. Paralelamente a isso, o poder público, junto com a coletividade, tem que se articular para implementar uma política de fiscalização e monitoramento, dentro e no entorno dessas áreas, capaz de garantir a integridade dos ecossistemas sob o seu domínio.

Para tanto, quando se trabalha com herança e simbolismo, deve-se ter uma abordagem em que o ponto de partida é a representação revelada pelos pontos de vista populares. E como forma de compreender o conceito de símbolo, Bourdieu (1976, p.82) afirma que, "é a resultante das condições sociais [...]".

Observa-se que os símbolos mais mencionados pelos entrevistados foram: o Açude Cedro, a Pedra da Galinha Choca, o Santuário N. Senhora Imaculada Rainha do Sertão, o Chalé da Pedra, a Lagoa dos Monólitos, a Pedra do Cruzeiro, a Serra do Estevão e a Gruta de São Francisco. Os resultados da pesquisa mostraram que a população tem esses pontos turísticos como os mais visitados. O Açude Cedro e o Chalé da Pedra são os mais requisitados $(26,35 \%$ e $25,75 \%$, respectivamente), seguidos do Santuário, com 18,36, e da Pedra da Galinha Choca, com 11,38 da preferência dos respondentes do questionário.

A pertinência do diálogo continua para comprovar que a conservação dos bens culturais deve e pode contribuir para o desenvolvimento do turismo local. Acredita-se que na atividade turística as mudanças, referentes à cultura, têm estabelecido uma relação simbiótica, de um lado o turismo pode ser e oferecer incentivos diversos para: 


\begin{abstract}
"manutenção e revitalização de diversas atividades culturais [...] da mesma forma, os efeitos que o turismo pode causar nas tradições locais podem ser desastrosos, e ao invés de reavivar a memória local, pode apagá-la ou descaracterizála". (BELFORT, 2004, p.09).
\end{abstract}

Ao perguntar sobre o que eles sabiam sobre a história de Quixadá, verificou-se certa apatia e desconhecimento nas respostas, de modo tal que pelos os três grupos consultados, apenas o grupo do governo sobressaiu-se um pouco melhor sobre o assunto.

Diante dessas conversas, pode-se ter a nítida impressão de que aquilo que era explanado pelos representantes do governo, se configurava em um conhecimento mecânico, sem emoção e sem representar uma identidade com a riqueza histórica local.

Desse modo, é imprescindível uma cooperação de todos os atores envolvidos para conhecer, ordenar e/ou classificar todos os bens que compõem o patrimônio cultural de Quixadá em prol da atividade turística.

Face ao exposto, cabe mencionar Mathieson e Wall (apud TULIK 1990, p.68-69), pois eles admitiam, já na década passada, com uma visão abrangente, que o turismo estimulava a existência e a reabilitação de sítios históricos, construções e monumentos, por meio de sua transformação em recurso recreacional.

Sendo assim, estudos internacionais mostram que o turismo cultural propicia a revitalização de atividades tradicionais de áreas em declínio, a redescoberta de sítios com propriedades específicas e de cidades históricas, estimulando a transformação de antigas habitações em acomodações turísticas, mantendo a estrutura e as características tradicionais.

Infere-se, que ao questionar esses pontos na pesquisa, compreendeu-se a real importância da história de Quixadá apenas no contexto geral de representatividade para o Estado, já que, no foco local, a amostra pesquisada mostrou-se inativa ao universo cultural existente em Quixadá.

Para tanto, é necessário adotar uma nova proposta para a imagem de lugar turístico com elementos culturais e naturais agregados permitindo que se tenha uma demanda turística, a qual permaneça mais tempo e interaja com a população local, respeitando suas crenças desenvolvimento sociocultural e seus hábitos contribuindo para 0 desenvolvimento sociocultural.

Vale ressaltar que a participação comunitária é uma prerrogativa para a implantação do turismo cultural, pois é através dela que se fortalecerão os traços de identidade junto com o seu patrimônio.

Sob essa ótica, procurou-se investigar a opinião dos quixadaenses sobre as perspectivas do turismo voltado ao patrimônio cultural da cidade. Apesar de seu potencial para o turismo cultural, o município de Quixadá não vem desenvolvendo atividades voltadas para este segmento, que causaria 
menos impactos no local, dada as implicações no planejamento diferenciado para os produtos turísticos culturais e no comportamento das pessoas interessadas neste tipo de atividade, contrária às práticas de turismo que vêm sendo incentivadas no município.

Constatou-se que a relação contraditória entre sociedade e natureza é antiga entre nós. Admite-se que, nos últimos anos, com a inserção de novas relações sociais de produção, esse quadro se agravou sensivelmente. É mister reconhecer que os mais antigos expressavam uma postura de mais respeito em relação ao meio ambiente dominante.

Como se vê, estimular o turismo cultural nas Unidades de Conservação, criar mecanismos de preservação de ambientes frágeis e incentivar a sustentabilidade no uso de seus recursos é o desafio assumido pelo Governo em resposta aos anseios do povo cearense. Nesse contexto, o belo, o singular, o exótico aparecem como incentivo ao sentimento de se contemplar e valorizar o que é do cearense, propiciar aos diferentes olhares o conhecer, o sentir para agir e conservar o patrimônio histórico, contribuindo, desse modo, para a sustentabilidade da gestão dos recursos naturais do Estado.

\section{Referências}

BELFORT, C. A relação entre turismo e cultura popular. Itinerários: revista científica de turismo. São Luís (MA), v. 01. n. 01. 2004. p.7-12.

BENI, M. C. Análise estrutural do turismo. 6 ed. São Paulo: SENAC, 2001.

BOMFIM, L.C.E. O turismo como alternativa de desenvolvimento local no município de Presidente Epitácio: representações sociais e culturais de identidade local. Dissertação (Mestrado em Desenvolvimento Local). Universidade Católica Dom Bosco (UCDB), Campo Grande, 2006.

BOURDIEU, P. A economia das trocas simbólicas. São Paulo: Perspectiva, 1976.

CANCLINI, N.G. O patrimônio cultural e a construção imaginária do nacional. Revista do Patrimônio Histórico e Artístico Nacional - IPHAN, Brasília, nํ.23,1994. p.95-111.

COSTA, J.E.C. Retalhos da História de Quixadá. Fortaleza: ABC Editora, 2002. 602p.

CRUZ, R.C. Política de turismo e território. São Paulo: Contexto, 2000. $167 p$.

MATHIESON, A.; WALL, G. Tourism: economic, physical and social impacts. Harlow: Longman Scientific \& Technical Editora, 1990.

MOTTA, F.C.P. Cultura e Organizações no Brasil. In: CALDAS, M.P; MOTTA, F.C.(Org.). Cultura organizacional e cultura brasileira. São Paulo: Atlas, 2006. p.25 - 37.

SANTOS, M. Espaço e método. São Paulo: Nobel, 1985.

VON BEHR, M. Quixadá: Terra dos Monólitos. São José dos Campos: Somos Editora, 2007. 303p. (Série Ecossistemas Brasileiros). 


\section{Notas}

1 Os profetas da chuva são pessoas da zona rural do Nordeste brasileiro que elaboram previsões de tempo e de clima, baseados em observações das mudanças do ecossistema, da atmosfera, de posição e visibilidade de corpos celestes, em sonhos, em rituais religiosos que se misturam com crenças indígenas ou outras formas de conhecimento. Na cidade de Quixadá ocorre, desde 1997, o Encontro Anual dos Profetas Populares do Sertão Central. O evento acontece a cada segundo sábado de janeiro, data transformada em Dia dos Profetas da Chuva pela Câmara de Vereadores do município. Disponível em: $<$ http://www.quixada.ce.gov.br> Acesso em 20 de maio de 2016.

2"O Cangaceiro Trapalhão", filmado em 1983, no distrito de Juatama - Quixadá. "O Quinze", inspirado no livro de Rachel de Queiroz, foi filmado em 2003, lançado nos cinemas em 2007; "O Auto da Camisinha", filmado em 2009, gravado em Juatama - Quixadá. "Gato Preto" dirigido pelo quixadaense Clébio Ribeiro, com previsão de estreia nacional para 2012, assim como "Área Q", em parceria entre as produtoras Reef Pictures Inc., ATC Entretenimentos e Estação Luz Filmes. Disponível em: <http://www.quixada.ce.gov.br> Acesso em 28 de maio de 2016.

Hermógenes Henrique Oliveira Nascimento: Secretaria Estadual do Meio Ambiente do Ceará, Fortaleza, CE, Brasil.

E-mail: henrique.sampa@gmail.com

Link para o currículo Lattes: http://lattes.cnpq.br/0195752487069939

Data de submissão: 29 de agosto de 2016

Data de recebimento de correções: 15 de outubro de 2016

Data do aceite: 15 de outubro de 2016

Avaliado anonimamente 